\title{
Effectiveness of an infant oral health care educational intervention on knowledge of dental students
}

This article was published in the following Dove Press journal:

Advances in Medical Education and Practice

16 August 2011

Number of times this article has been viewed

\author{
Nouf S AlHammad' \\ Fouad S Salama ${ }^{2}$ \\ 'Pediatric Dentistry and Orthodontics \\ Department, King Saud University \\ College of Dentistry, Riyadh, \\ Kingdom of Saudi Arabia; \\ ${ }^{2}$ Growth and Development \\ Department, College of Dentistry, \\ University of Nebraska Medical \\ Center, Omaha, NE, USA
}

Background: This study evaluated the effectiveness of an infant oral health care educational intervention on the knowledge of female dental students at King Saud University in Riyadh city. Methods: One hundred and twenty-eight students participated in the study. The participants were from different levels in the dental college, ie, second year (D2), third year (D3), fourth year (D4), and fifth year (D5). Assessment by questionnaire was completed immediately before and after a 14-minute educational intervention, in the form of a PowerPoint presentation and video on oral health of infants for dental students. The 18-item multiple-choice questionnaire was based on information presented in the presentation.

Results: A significant difference $(P<0.001)$ was found between average pretest scores $(9.30 \pm 2.24)$, and average post-test scores $(12.56 \pm 2.05)$. The highest percentage of improvement in the post-test as compared with the pretest was recorded for group D2 (50.6\%) followed by D3 (40\%), D4 (35\%), and D5 (23\%). One hundred and twenty-six (98.4\%) study participants found the presentation helpful in improving their understanding of infant oral health, and 77 $(60.2 \%)$ were very satisfied with the presentation. Sixty-six participants $(51.6 \%)$ reported that the presentation was very effective in teaching them about infant oral health, and $83(65 \%)$ were very likely to incorporate this information into their daily practice.

Conclusion: A 14-minute PowerPoint and video educational intervention was effective in teaching basic information about infant oral health to dental students.

Keywords: dental care for children, education, dental, infant, health knowledge

\section{Introduction}

The Center for Disease Control and Prevention reports that dental caries is the most prevalent infectious disease in US children. ${ }^{1}$ Dental caries is five times more common than asthma and seven times more common than hayfever in children. ${ }^{1}$ Early childhood caries is a particularly virulent form of caries, beginning soon after tooth eruption, developing on smooth surfaces, progressing rapidly, and having a lasting detrimental impact on dentition..$^{2-7}$ This disease affects the general population, but is 32 times more likely to occur in infants of low socioeconomic status, whose mothers have a low education level, and who consume sugary foods. ${ }^{8}$ Caries in primary teeth can affect children's growth, diminish overall quality of life, and result in significant pain and potentially life-threatening infection. ${ }^{9-15}$ A study of caries prevalence, severity, and patterns among preschool children in Riyadh, Saudi Arabia, reported that the prevalence and severity of caries was very high in the study population, and most children had posterior tooth caries. ${ }^{16}$ A statewide oral health survey in Arizona involving 5171 preschool children found that children as young as 10 months had frank cavities on their maxillary incisors. ${ }^{17}$
Correspondence: Nouf S AlHammad Department of Pediatric Dentistry and Orthodontics, King Saud University College of Dentistry, PO Box 5967, Riyadh I I432, Kingdom of Saudi Arabia Tel +966505472893

Fax +966 I47857I 9

Emailnhammad02@yahoo.com 
The "dental home" is the ongoing relationship between the dentist and the patient, inclusive of all aspects of oral health care delivered in a comprehensive, continuously accessible, coordinated, and family-centered way. ${ }^{18}$ The American Academy of Pediatric Dentistry (AAPD) recognizes that infant oral health is the foundation upon which preventive education and dental care must be built to enhance the opportunity for a lifetime free from preventable oral diseases. ${ }^{19}$ Recognizing that allied health professionals and community organizations must be involved as partners to achieve this goal, the AAPD has made recommendations for perinatal oral health care, caries risk assessment, anticipatory guidance, preventive strategies, and appropriate therapeutic interventions to be followed by stakeholders in perinatal and pediatric oral health. ${ }^{19,20}$ The AAPD recommends that every expectant mother should receive a comprehensive oral health evaluation and establish a dental home as early as possible during pregnancy. ${ }^{20}$ The AAPD also recommends that every infant should receive an oral health risk assessment from a primary health care provider or qualified health care professional by 6 months of age. ${ }^{20}$ The AAPD also encourages parents and other care providers to help every child establish a dental home by 12 months of age. ${ }^{21}$

Educating dental students on different aspects of infant oral health may increase their interest in providing oral care for infants. Timely delivery of educational information to populations at high risk for developing caries is the ultimate goal of early assessment. Educating health care professionals, including dental students, is essential before awareness can be spread within high-risk populations. Two important areas where dental students and primary health care providers can contribute to improving oral health in children are by encouraging parents to find a dental home (and make an appropriate referral to one if necessary) and by giving parents appropriate anticipatory guidance. $^{22}$

It has been reported that dentists who perform infant oral health examinations during dental school are significantly more likely to undertake oral examinations in children younger than 3 years of age in their subsequent practice. ${ }^{23}$ It has also been reported that clinical exposures to infants and toddlers in dental school were strongly associated with a positive view of caring for preschool children by general practitioners. ${ }^{24}$ Another study of dental students found that rotations with young patients and preventive clinics increased the number of dental students who recommended a first dental visit before the age of 1 year from $3 \%$ to $30 \%{ }^{25}$

A survey in 2001 indicated that there are varying degrees of acceptance about teaching infant oral health in our dental schools. ${ }^{26}$ The variety of experiences ranged from none, to lecture only, to limited hands-on experience, to consistent experience for all students. ${ }^{26}$ Another study reported variations in opinion regarding basic knowledge of infant oral health among dental students and inconsistencies with regard to desired outcomes of educational and clinical experiences. ${ }^{27}$ An educational video presentation for pediatric medicine and family medicine residents was evaluated and demonstrated that more infant oral health training for medical professionals is needed. The study participants reported the information was useful and the vast majority said it would have a major impact on their daily activities. ${ }^{22,28}$ The authors concluded that an educational video intervention was an effective tool in teaching pediatric medicine and family medicine residents about basic infant oral health.

Dental education provides an opportunity to help improve infant oral health, and academic institutions would benefit by examining models to educate dental students on how best to address the oral health needs of infants. However, research on educational interventions related to infant oral health care is limited. We hypothesized that viewing a concise, educational visual presentation would provide dental students with instructive information, a targeted approach to infant oral health, and anticipatory guidance. Therefore, the aim of this study was to evaluate an infant oral health educational intervention targeted to female students at the King Saud University College of Dentistry.

\section{Methods}

This research project, including pretest and post-test assessment, was approved by the College of Dentistry Research Center Ethical Committee at King Saud University. The study evaluated the effectiveness of an infant oral health care educational presentation on the knowledge of female students attending the dental college at King Saud University, Riyadh city. Participants were given an educational assessment in the form of a questionnaire, which they completed immediately before and immediately after the introduction of an educational intervention produced and tested in other studies. ${ }^{22,28}$ The educational intervention used the AAPD guidelines to produce a video that included a PowerPoint presentation of infant oral health for dental students. The instructional video took approximately 7.25 minutes, and was followed by a PowerPoint presentation of 6.24 minutes. The presentation provides an informative and concise presentation of infant oral health for health care professionals designed to instruct dental students in: how to perform an infant oral screening; how to identify infants at increased risk for oral health problems; when to make appropriate referrals; and how 
to provide parents with appropriate anticipatory guidance. The topics covered included: how to perform an infant oral health examination; what to look for in an infant oral health examination; how to recognize incipient and gross carious lesions; timing of the first dental visit; primary teeth eruption and exfoliation; periodicity of dental screening; appropriate use of fluoride supplementation; and emergency care for infant oral trauma. In addition, the presentation reviewed anticipatory guidance on appropriate feeding and proper oral hygiene for infants.

An 18-item multiple-choice questionnaire based on the information presented in the video and the PowerPoint presentation was designed to assess dental students' knowledge of these important aspects of infant oral health. The questionnaire was given immediately before and after the educational intervention. The pretest questionnaire included the following information to describe the students participating in the study: study year; any formal or informal training in infant oral health prior to the presentation; and how they rated their knowledge of infant oral health. The post-test included six additional questions to evaluate student's opinions of the importance, effectiveness, and usefulness of the presentation in expanding their knowledge of infant oral health. The participants were asked about their satisfaction with the educational component of the presentation, to rate their knowledge of infant oral health after the presentation, if there was anything they would like to change or add to the presentation, and if they were likely to implement the information in their practice. The pretest and post-test were anonymous, identified by the same unique number, and not linked to the student.

\section{Statistical analysis}

Statistical analyses were performed using SPSS software (v 17.0; SPSS Japan Inc, Tokyo, Japan). Statistical differences between individual scores and total scores on the knowledge-based questionnaire were evaluated by comparing correct pretest and post-test score differences using the paired $t$-test and the Tukey's multiple comparison post hoc test. Blank responses were scored as incorrect.

\section{Results}

One hundred and twenty-eight female dental students completed the study. Twenty-four (18.8\%) were in D2, 31 (24.2\%) were in D3, 35 (27.3\%) were in D4, and $38(29.7 \%)$ were in D5. The first two groups (D2 and D3) had no previous formal or informal training in infant oral health, while the other two groups (D4 and D5) had previous pediatric dentistry courses for 1 year (D4), and 2 years (D5). The average score on the pretest was $9.30 \pm 2.24$, which increased to $12.56 \pm 2.05$ on the post-test. This difference was statistically significant $(P<0.001)$. In addition, the average scores on the pretest were significantly different $(P<0.001)$ than the post-test scores for all the groups (D2-D5, Table 1). Using a pairedsample correlation, a significant correlation was found between the average score on the pretest and post-test for D4 and D5, while no correlation was found between the pretest and post-test average score for the two other groups (D2 and D3).

The highest percentage of improvement in the post-test as compared with the pretest was recorded for group D2 (50.6\%) followed by D3 (40\%), D4 (35\%), and D5 (23\%). For the pretest average scores, the groups with previous training in infant oral health (D4 = 10.14 and D5 = 10.18), had significantly higher scores than the groups with no previous training $(\mathrm{D} 2=8.08$ and D3 $=8.19)$. For the average post-test scores, D4 and D5 students had higher scores (13.71 and 12.50) than D2 and D3 (12.17 and 11.65) with a post-test score for D4 that was significantly higher than that for the other three groups $(P<0.001)$.

One hundred and twenty-six (98.4\%) study participants found the presentation helpful in improving their understanding of infant oral health, and 77 (60.2\%) were very satisfied with the presentation. Sixty-six (51.6\%) participants reported that the presentation was very effective in teaching them about infant oral health, $83(65 \%)$ were very likely to incorporate this information into their daily practice, $42(33 \%)$ were somewhat likely, and three $(2 \%)$ were not likely to use this information in their practice (Figure 1). When asked to rate their knowledge of infant oral health after the presentation, 97 (75.8\%) said their knowledge was general, 12 (9.4\%) said it was extensive, while 19 (14.8\%) had minimal knowledge, but when asked to rate their knowledge before the presentation, 47 (36.7\%) said it was general, one $(0.8 \%)$ said her knowledge was extensive, while the majority $(80[62.5 \%)])$ reported minimal knowledge before the presentation (Figure 2). Regarding the question

Table I Difference between total pretest and post-test scores for all year groups

\begin{tabular}{lllll}
\hline Study groups & $\mathbf{n}$ & $\begin{array}{l}\text { Mean (pretest and } \\
\text { post-test scores) }\end{array}$ & SD & P value \\
\hline D2 & 24 & 4.083 & 2.104 & 0.000 \\
D3 & 31 & 3.452 & 2.631 & 0.000 \\
D4 & 35 & 3.571 & 2.004 & 0.000 \\
D5 & 38 & 2.316 & 1.933 & 0.000 \\
\hline
\end{tabular}

Abbreviation: SD, standard deviation. 


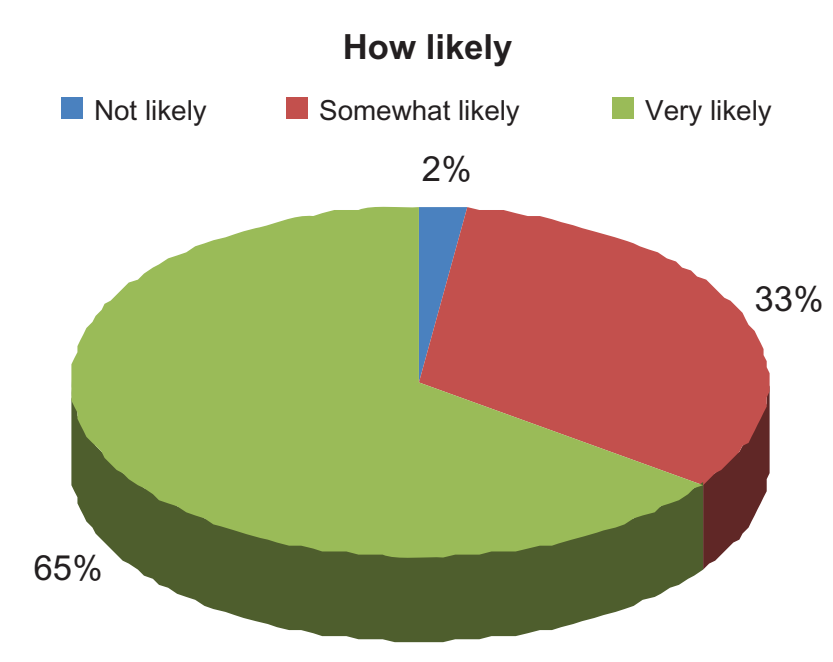

Figure I Answers to the question "How likely are you to implement this information into your practice?"

about the things they would like to change in the presentation, $39(30 \%)$ said they would make changes. Thirty-one (79.5\%) participants said they would wish to slow down the presentation, six (15.4\%) wished the presentation had been longer and had provided more information, while two $(5.1 \%)$ respondents wanted the information presented to be more basic with fewer numbers. The most common correct answers in the pretest were for the questions about the things the dentist does at the infant's first dental visit (90\%) and the beginning of primary tooth eruption (88\%), while the least correct answers were for the questions about the amount of juice a child should consume per day and the age at which fluoride varnish should first be applied (16\%). For the post-test, the most common correct answers were to questions about the most common chronic diseases in children (98\%) and the beginning of primary tooth eruption (97\%), while the least correct answers were to questions about the complications of primary tooth decay (37.5\%) and the time at which parents should begin infant oral health practice $(39 \%)$.

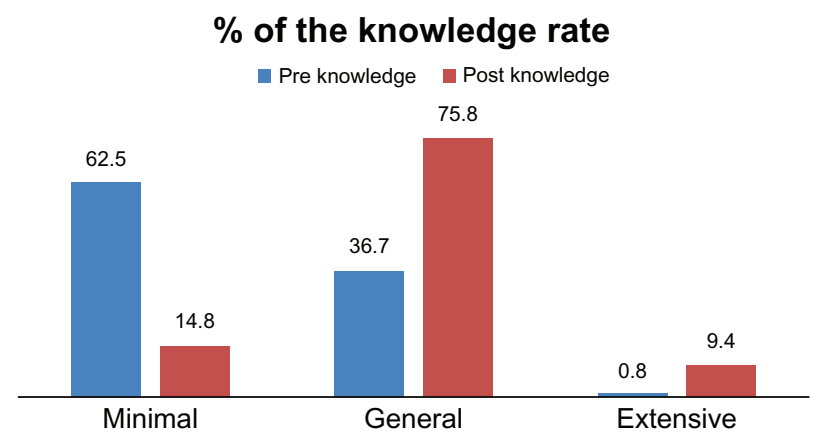

Figure 2 Participants' rating of knowledge before and after the educational presentation.

\section{Discussion}

Education seems to be the key to prevention of infant oral health problems, and if health professionals do not have the appropriate education, they themselves cannot provide education to parents. It is important for all health care professionals, including dental students, to have the education necessary to promote infant oral health. However, it is even more important for dental professionals to participate actively in infant oral health education. Therefore, this study aimed to educate female dental students at King Saud University College of Dentistry and to evaluate the effectiveness of a 14-minute infant oral health program intervention. The study targeted all D2, D3, D4, and D5 students $(\mathrm{n}=167)$. One hundred and twenty-eight students participated in the study (response rate $77 \%$ ). With a sample size of 128 and under the conditions of $\alpha=0.05$ and $\beta=0.2$, the power of the test was $>0.8$. The results demonstrated that this method of teaching was effective. These findings echo those of previous studies which evaluated changes in dental students' knowledge, confidence, opinions, and behaviors following a curricular intervention for infant and toddler oral health using a pretest and post-test study design, and reported that $88 \%$ of the students enrolled in the intervention stated that they were more likely to treat children in this age group following this clinical experience. ${ }^{29}$ In the present study, three ( $2 \%)$ were not likely to use this information in their practice, although their average pretest and post-test scores showed an increase, which indicates that they too learned from the presentation, even though they reported that they were not likely to use the information given.

It has been reported that while most schools provide their students with exposure to the concept of infant oral examination, only one in four includes hands-on experience with related procedures. ${ }^{26}$ To address the current gaps in dental education and to promote the involvement of dental students in the care of infants, this study evaluated the use of a concise educational video intervention. It provided dental students with the steps of the infant oral examination, instructive information, and a targeted approach to infant oral health and anticipatory guidance. After the presentation, infant oral health knowledge increased in all dental classes.

In this study, educating dental students was effective. Providing education during residency training, before practice patterns have become rigidly established, has been successful. It has been reported that integration of an early childhood caries prevention program into the clinical medical education curriculum resulted in dental caries becoming the eleventh most common diagnosis seen in the clinic, when previously 
it did not appear in the top $40 .{ }^{30-32}$ In contrast, delivering effective education after completion of residency training is challenging, given that the evidence suggests traditional ongoing didactic medical education does not improve physician performance. ${ }^{33}$

In this study, there was a positive correlation between class/year in dental school and knowledge of infant oral health. In contrast with our study, Chung et al found that first-year dental students were more likely than fourth-year dental students to rank the first dental visit as important. ${ }^{27}$

In the present study, there was a significant correlation between class and score on the pretest and post-test. The higher the dental class, the higher the score. The differences between D2, D3, D4, and D5 students may be a reflection of the greater clinical experience of D4 and D5 students. If so, the clinical experiences in dental school may modify students' beliefs and attitudes about infant oral care. The differences between years may also be due to cohort differences instead of differences in educational level. In addition, influences of unmeasured variations in class composition and the background of students may have confounded the findings. Because this study surveyed students from one institution, the results may not be generalizable to all dental students in other dental schools. In spite of these assumptions, the differences found among the groups are likely to approximate the true differences. In the present study, the post-test choices showed that the students learned from the presentation.

Participants reporting formal training in infant oral health correlated highly with reported knowledge of infant oral health, but those reporting no previous training in infant oral health correlated less with reported knowledge of infant oral health. There was a significant correlation between post-test and formal training, but there was no correlation between post-test and no previous training. The highest percentage of improvement in the post-test as compared with the pretest was recorded for group D2 followed by D3, D4, and D5. For the average pretest scores, the groups with previous training in infant oral health (D4 and D5) had significantly higher scores than the groups with no previous training (D2 and D3). For the average post-test scores, D4 and D5 students had higher scores than D2 and D3 students, with the post-test score for D4 being significantly higher than for the three other groups $(P<0.001)$. These findings echo those of previous studies done by general dentists, physicians, and family medicine and pediatric medicine residents, who reported that they did not receive adequate education concerning oral health. ${ }^{22,34-36}$
The findings of this study need to be considered in the context of its limitations. The results are limited by the nature of the design and size of the sample. Only $77 \%$ of students in one dental school participated in this study, and it remains to be seen if the results can be generalized to a larger group from other dental colleges. Also, this study was completed in a single sitting, and longer-term follow-up must be completed to determine permanent changes in practice habits and long-term retention of infant oral health knowledge and information. Ideally, this change would be tracked throughout training and beyond. Additionally, all data collected in this study were selfreported. Students may or may not have answered questions honestly about practice habits and oral health values. The differential response rates for dental students may have played a role in this study, as well as variation in class composition. The most likely response bias is that those students who had more confidence in their knowledge were more likely to respond, suggesting that true results may have shown lower levels of infant oral health knowledge among students. Although student biographical information was collected at baseline, the participants were not randomly selected. Rather, they showed a desire to participate or made the decision to participate in this study. Follow-up studies should determine if this is the best method for delivery of information compared with other possible delivery methods with regard to information retention and practice changes. Finally, it would be interesting to have additional follow-up studies that answer some of the limitations of this study, such as a follow-up survey and open-ended interviews regarding actual behavior change rather than just knowledge change. In addition, it would be interesting to follow these students into their future jobs and see if they really do act upon their knowledge. In summary, this cross-sectional educational program and survey was undertaken among 128 dental students, and it would be easy and feasible to implement this program into the dental school curriculum.

\section{Conclusion}

This study demonstrated the effectiveness of a 14-minute video and PowerPoint slide presentation to communicate information on infant oral health to dental students. Dental students lack adequate knowledge on infant oral health, so there is a need to increase their knowledge through effective teaching. The King Saud University College of Dentistry should add infant oral examination to its pediatric dentistry course, given that the students currently only practice on children over 3 years of age. Our study participants reported greater interest and increased knowledge, and that this information will change their daily practice for infant oral health. 
More research should be done on how to best deliver information on infant oral health to dental students and long-term retention of the information. The educational intervention used in this study provided dental students with the steps of the infant oral examination and instructive information, as well as a targeted approach to infant oral health and anticipatory guidance. Knowing this information plus hands-on experience with related procedures will increase the student's ability to examine infants, participate more in the prevention of oral diseases in infants, and improve parent education, which will improve the oral health status of infants in society.

\section{Acknowledgments}

The authors are grateful to all the students who participated in the study and to Mr Nassr Al-Maflehi for his help during the statistical analysis. This research was registered at the College of Dentistry Research Center, King Saud University.

\section{Disclosure}

The authors report no conflicts of interest in this work.

\section{References}

1. US Department of Health and Human Services. Oral Health in America: A Report of the Surgeon General. Washington, DC: US Department of Health and Human Services, National Institute of Dental and Craniofacial Research, National Institutes of Health; 2000.

2. Gray MM, Marchment MD, Anderson RJ. The relationship between caries experience in deciduous molars at 5 years and in first permanent molars of the same child at 7 years. Community Dent Health. 1991;8:3-7.

3. Grindefjord M, Dahllof G, Modeer T. Caries development in children from 2.5 to 3.5 years of age: a longitudinal study. Caries Res. 1995;29: $449-454$.

4. O'Sullivan DM, Tinanoff N. The association of early dental caries patterns with caries incidence in preschool children. J Public Health Dent. 1996;56:81-83.

5. Johnsen DC, Gerstenmaier JH, DiSantis TA, Berkowitz RJ. Susceptibility of nursing-caries children to future approximal molar decay. Pediatr Dent. 1997;19:37-41.

6. Heller KE, Eklund SA, Pittman J, Ismail AL. Associations between dental treatment in the primary and permanent dentitions using insurance claims data. Pediatr Dent. 2000;22:469-474.

7. Nowak AJ, Warren JJ. Infant oral health and oral habits. Pediatr Clin North Am. 2000;47:1043-1066.

8. Drury TF, Horowitz AM, Ismail AL. Diagnosing and reporting early childhood caries for research purposes. J Public Health Dent. 1999;59:198-200.

9. Fleming P, Gregg TA, Saunders ID. Analysis of an emergency dental service provided at a children's hospital. Int J Paediatr Dent. 1991;1:25-30.

10. Acs G, Lodolini G, Kaminsky S, Cisneros GJ. Effect of nursing caries on body weight in a pediatric population. Pediatr Dent. 1992;14: 302-305.

11. Schwartz S. A one-year statistical analysis of dental emergencies in a pediatric hospital. J Can Dent Assoc. 1994;60:959-969.
12. Ayhan H, Suskan E, Yildirim S. The effect of nursing or rampant caries on height, body weight, and head circumference. J Clin Pediatr Dent. 1996;20:209-212.

13. Sheller B, Williams BJ, Lombardi SM. Diagnosis and treatment of dental caries-related emergencies in a children's hospital. Pediatr Dent. 1997;19:470-475.

14. Low W, Tan S, Schwartz S. The effect of severe caries on the quality of life in young children. Pediatr Dent. 1999;21:325-326.

15. Acs G, Pretzer S, Foley M, Ng MW. Perceived outcomes and parental satisfaction following dental rehabilitation under general anesthesia. Pediatr Dent. 2002;23:419-423.

16. Wyne AH. Caries prevalence, severity, and pattern in preschool children. J Contemp Dent Pract. 2008;9:24-31.

17. Douglass JM, Tinanoff N, Tang JM, Altman DS. Dental caries patterns and oral health behaviors in Arizona infants and toddlers. Community Dent Oral Epidemiol. 2001;29:14-22.

18. American Academy of Pediatric Dentistry. AAPD reference manual 2009-2010; definition of dental home. Pediatr Dent. 31:10.

19. American Academy of Pediatric Dentistry. AAPD reference manual 2009-2010; guideline on infant oral health care. Pediatr Dent. 31 : 95-99.

20. American Academy of Pediatric Dentistry. AAPD reference manual 20092010; guideline on perinatal oral health care. Pediatr Dent. 31:90-94.

21. American Academy of Pediatric Dentistry. AAPD reference manual 2009-2010; policy on the dental home. Pediatr Dent. 31:22-23.

22. Salama F, Kebriaei A, Rothe V. Effectiveness of a basic training presentation on infant oral health care for family medicine residents. Pediatr Dent. 2010;32:106-109.

23. Seale NS, Casamassimo PS. Access to dental care for children in the United States: a survey of general practitioners. JAm Dent Assoc. 2003; 134:1630-1640.

24. Cotton KT, Seale NS, Kanellis J, Damiano PC, Bidaut-Russell M, McWhorter AG. Are general dentists' practice patterns and attitudes about treating Medicaid-enrolled pre-school age children related to dental school training? Pediatr Dent. 2001;23:51-55.

25. Wandera A, Feigal RJ, Green T. Preparation and beliefs of graduates of a predoctoral infant oral health clinical program. Pediatr Dent. 1998;20:331-335.

26. McWhorter AG, Seale NS, King SA. Infant oral health education in US dental school curricula. Pediatr Dent. 2001;23:407-409.

27. Chung MH, Kaste LM, Koerber A, Fadavi S, Punwani I. Dental and medical students' knowledge and opinions of infant oral health. $J$ Dent Educ. 2006;70:511-517.

28. Kebriaei A, Rothe V, Pitner S, Balluff M, Salama F. Effectiveness of a basic training presentation on infant oral health care for pediatric medicine residents. J Clin Pediatr Dent. 2008;33:143-146.

29. Fein JE, Quinonez RB, Phillips C. Introducing infant oral health into dental curricula: a clinical intervention. J Dent Educ. 2009;73:1171-1177.

30. Strecher VJ, O’Malley MS, Villagra VG, Campbell EE, Gonzalez JJ, Irons TG. Can residents be trained to counsel patients about quitting smoking? results from a randomized trial. J Gen Intern Med. 1991; 6:9-17.

31. Lazarus K, Weinsier RL, Boker JR. Nutrition knowledge and practices of physicians in a family-practice residency program: the effect of an education program provided by a physician nutrition specialist. $\mathrm{Am} J$ Clin Nutr. 1993;58:319-325.

32. Graham E, Negron R, Domoto P, Milgrom P. Children's oral health in the medical curriculum: a collaborative intervention at a universityaffiliated hospital. J Dent Educ. 2003;67:338-347.

33. Davis D, O'Brien MA, Freemantle N, Wolf FM, Mazmanian P, Taylor-Vaisey A. Impact of formal continuing medical education: do conferences, workshops, rounds, and other traditional continuing education activities change physician behavior or health care outcomes? JAMA. 1999;282:867-874. 
34. Ismail AI, Nainar SM, Sohn W. Children's first dental visit: attitudes and practices of US pediatricians and family physicians. Pediatr Dent. 2003;25:425-430.

35. Dela Cruz GG, Rozier RG, Slade G. Dental screening and referral of young children by pediatric primary care providers. Pediatrics. 2004; 114:e642-e652.
36. Salama F, Kebriaei A. Oral care for infants: a survey of Nebraska general dentists. Gen Dent. 2010;58:182-187.

\section{Publish your work in this journal}

Advances in Medical Education and Practice is an international, peerreviewed, open access journal that aims to present and publish research on Medical Education covering medical, dental, nursing and allied healthcare professional education. The journal covers undergraduate education, postgraduate training and continuing medical education including emerging trends and innovative models linking education, research, and healthcare services. The manuscript management system is completely online and includes a very quick and fair peer-review system. Visit http://www.dovepress.com/testimonials.php to read real quotes from published authors.

Submit your manuscript here: http://www.dovepress.com/advances-in-medical-education-and-practice-journal 